BRYDLX. If. P. Iathstereopic reegrition and cerebral dominance. Perceptual \& 110 tor Skills, 1964.19 .686$.

BRYDEN. II. P. Tachistoseopic recoonition, handedness, and cerebral dominance. Neuropsychlogia, 1965, 3, 1-8.

GESCHWIND, N. Disconnexion syndromes in animals and men. Brain, 1965, 88, 585-644.

GRAFSTEIN, B, Organization of callosal connections in supra-sylvian gyrus of cat. Journal of Neurophysiology, 1959, 22, 504-515.

HIRATA, K., \& OSAKA, R, Tachistoscopic recognition of Japanese letter materials in left and right visual fields. Psychologia, 1967, 10, 7-18.

HERON, W. Perception as a function of retinal locus and attention. American Joumal of Psychology, 1957, 70, 38-48.

JONES, M. H., \& JONES, F. N. The relationship of verbal reaction time to hemisphere of entry of a visual stimulus. American Psychologist, $1947,2,408$.

KIMURA, D. Cercbral dominance and the perception of verbal stimuli. Canadian Joumal of Psychology, 1961, 15, 166-171.

McRAE, D. L., BRANCH, C. L., \& MILNER, B. The occipital horns and cerebral dominance. Neurology, 1968, 18, 95-98.

MILNER, B. Brain mechanisms suggested by studies of temporal lobes. In C. H. Millikan and F. L. Darley (Eds.), Brain mechanisms underlying speech and language. New York: Grune \& Stratton, 1967

MILNER, B., BRANCH, C., \& RASMUSSEN, T. Evidence for bilateral speech representation in some non-right-handers. Transactions of the American Neurological Association, 1966, 91 306-308.

MINNUCI, P. K., \& CONNORS, M. M. Reaction time under three viewing conditions: Binocular, dominant eye, and non-dominant eyc. Journal of Experimental Psychology, 1964,67, 268-275.

PENFIELD, W., \& ROBERTS, L. Speech and brain mechanisms. Princeton: Princeton University Press, 1959.

POFFENBERGER, A. T. Cited in E. G. Ettlinger (Ed.), Functions of the corpus callosum. Boston: Little, Brown, 1965. P. 101.

RIGGS, L. A., ARMINGTON, J, C., \& RATLIFF, F. Motions of the retinal image during fixation. Joumal of the Optical Society of America, 1954,44, 315-321.

SATZ, P., ACHENBACH, K., \& FENNEL, E. Correlations between assessed manual laterality and predicted speech laterality in a normal population. Neuropsychologia, 1967 , 5, 295-310.

SMITH, K. U. Bilateral integrative action of the cerebral cortex in man in verbal association and sensory motor co-ordination. Joumal of Experimental Psychology, 1947, 37, 367-376.

SPERLING, G. Successive approximations to a model for short term memory. Acta Psychologia, 1967, 27, 285-292.

SPERRY, R. W. Hemispheric deconnection and unity in conscious awareness. American Psychologist, 1968, 23, 723-733.

SPERRY, R. W., \& GAZZANIGA, M. S. Language following surgical disconnection of the hemispheres. In C. H. Millikan and F. L. Darley (Eds.), Brain mechanisms underlying speech and language. New York: Grune \& Stratton, 1967.

TEITELBAUM, H., SHARPLESS, S. K., \& $B Y C K, R$. Role of somatosensory cortex in interhemispheric transfer of tactile habits. Journal of Comparative \& Physiological Psychology, 1968, 66, 623-632.

WADA, J, \& RASMUSSEN, T, Intracarotid injection of sodium amytal for the lateralization of cerebral speech dominance: Experimental and clinical observations. Journal of Neurophysiology, 1960, 17, 266-282.

ZURIF, E. B., \& BRYDEN, M. P. Familial handedness and left-right differences in auditory and visual perceptions. Neuropsychologia, 1969, 7, 179-187.

\title{
Structure and short-term memory ${ }^{1}$
}

\section{WILLIAM A. STOCK, Iowa State University, Ames, Iowa 50010}

Fifty-six undergraduates participated in a probe experiment investigating the effects of list structure and rate of presentation on recall. Very strong serial-position effects were found, with structured lists exhibiting higher recall and a von Restorff effect. Rate of presentation did not result in significant differences.

A theory of immediate memory has been proposed (Waugh \& Norman, 1965; Norman, 1966). This is a two-store theory, composed of a limited-capacity short-term memory (STM) and a long-term memory (LTM). "Rehearsal," i.e., attending to an item in order to increase its strength, preserves items in STM and makes it possible for an item to make the transition to LTM. All items in STM have the same probability of making the transition to LTM; therefore, if rehearsal is restricted to only the most recently presented item, the longer an item is in STM, the less its chances are for transition. The Waugh and Norman model accounts for serial-position (SP) effects in a method of their invention, the probe method. This technique generates a monotonic SP curve, with probability of correct recall a function of the number of items intervening between the to-be-recalled (critical) item and the occurrence of the probe at the end of the list. The critical item is the item following the first occurrence of the probe. Items furthest from the end of the list are recalled poorest.

Another theory, Feigenbaum \& Simon's (1962), is based on the supposition that persons act as information-processing systems. The most relevant aspect of their theory to the present study is the anchor-point hypothesis. That is, a memory processor locates anchor points in the stimuli stream and processes the stimuli items by "tying them" to these anchor points. In homogeneous lists, it is most likely that the two ends of the list provide the anchor points.
NOTES

1. Supported by NSF Grant GB-8013 to Dr. Paul Rozin. We are grateful to Dr. Burton Rosner and Dr. Paul Rozin for advice, criticism, and

2. Happily, the ambidextrous Śs did not show a visual field bias with respect to the number or nature of the errors they committed Like the righthanded group, however, the confusion errors the ambidextrous Ss made were primarily visual: ight visual confusions to only one auditory confusion.

In the probe paradigm, with "rehearsal" held constant, these two theories predict different results when lists are composed of two successive sets of stimulus items (half digits, half colors). The Feigenbaum and Simon theory would predict a von Restorff effect (a scallop effect at the point of bifurcation), while the Waugh and Norman theory would predict a monotonic curve. Several predictions were made in the present study. It was hypothesized that (1) unstructured lists would generate SP curves identical in nature to those reported by Norman (1966), (2) that overall recall for structured lists would be higher than for unstructured lists, (3) that the effects of rate of presentation would not differ, and finally, (4) structured lists were expected to produce a von Restorff effect at the point of bifurcation of the lists.

\section{SUBJECTS}

The Ss were 56 undergraduate volunteers, who received course credit for their participation.

\section{LISTS}

A 2 by 2 by 11 factorial design was formulated. Lists were presented in either a structured or unstructured manner and at one of two rates of presentation. The probe occurred at 11 SPs.

The stimulus populations consisted of digit words $(1,2,3,4,5,6,7,8,9,0,12)$ and color words (black, white, pink, brown, blue, tan, beige, red, green, gold, gray, orange). Zero was pronounced "oh" and orange was pronounced "ornge."

The experimental task involved listening to a stimulus list and then recalling the critical digit. Ss were able to recognize the probe only by realizing that the final item had been said. It had been explained that all lists had an equal number of items. Half the time the probe was a digit and half the time it was a color. The probe occurred at Positions 1 through 11 in the lists; the critical item could thus occur in Positions 2 through 12.

Structured lists were constructed by drawing, approximately at random, six digits and six colors from the populations. 


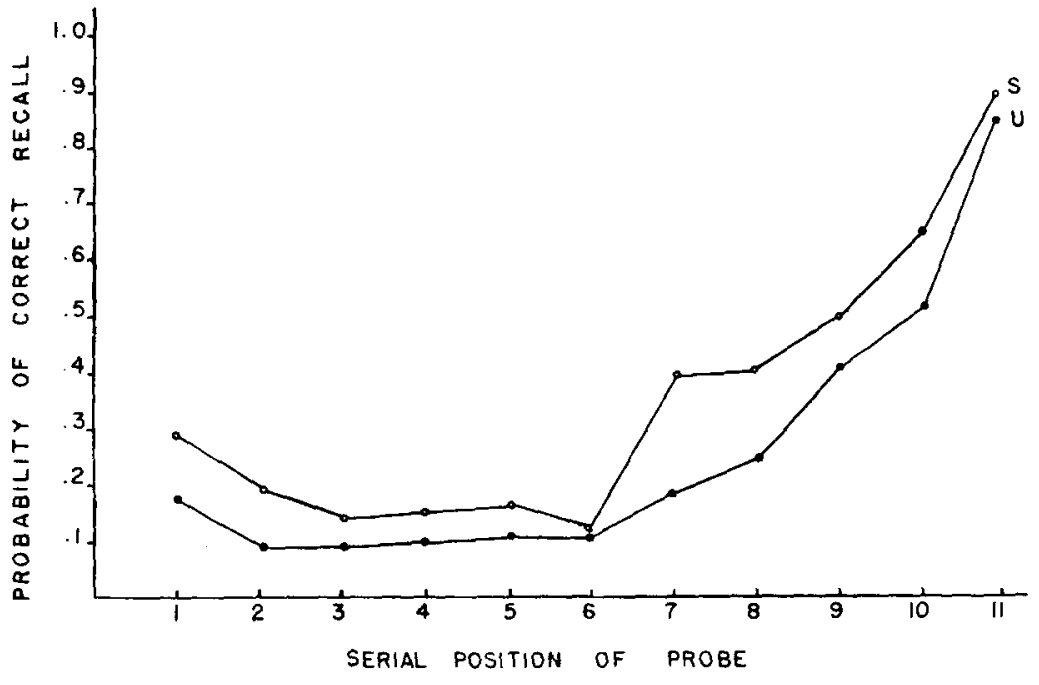

No word was allowed to occur twice in the same list. The probe, by definition, occurred twice. On half the trials the six digits preceded the six colors, and on the other half of the trials the colors preceded the digits.

For the unstructured lists, the same restrictions held, with the exception that the six digits and six colors were randomly ordered within each list. List $i$ of the set of unstructured lists used the exact same items as structured List i. Similarly, the probe was the same word and in the same position in each corresponding list. The 11 SPs were tested 10 times randomly across the set of trials.

Each set of 110 lists was tape-recorded twice for each rate of presentation, a slow rate of one item per second and a fast rate of four items per second. List items for the slow-rate-of-presentation tapes were pronounced in a clipped fashion so that duration of items at both rates was approximately equal. Thus, there were four tapes, each of which contained 220 trials. Ten practice trials were also recorded on each tape.

\section{PROCEDURE}

A Wollensak 5730 tape recorder was used for stimulus presentation to an entire experimental group. Waugh \& Norman's (1965) method of restricting rehearsal was followed, accomplished by instructing $S$ to "think only of the most recently presented item in each list." Ss received rest intervals of $2 \mathrm{~min}$ after $35,25,25$, and 25 trials of the first half of the session, a 5-min break between halves of the session, and 2-min breaks in the second half, as in the first. During the $5-\mathrm{min}$ break, the instructions were briefly reviewed. Ss were required to give a response for each list. They recorded their own responses on dittoed answer sheets.
Fig. 1. Probability of correct recall at each serial position of the probe for all trials of the structured (S) and unstructured (U) lists.

1968). It seems appropriate to raise this point as a possible alternative explanation.

Similarly, in the Norman model, modification of the function of the rehearsal mechanism may account for the present findings. One alternative, if ease of rehearsal was dependent upon stimulus structure, then rehearsal, hence recall, would be facilitated. For example, if the lists were divided into unequal spans, e.g., a two-thirds span and a one-third span, each composed of different classes of items, recall would be very high for the one-third-span items. Extending this, if lists were broken up into equal multiple subspans, multiple von Restorff effects, a scalloped SP curve, would probably occur. Here "chunking" capacity of immediate memory would produce diminishing returns as complexity increased beyond absolute channel capacity. The Feigenbaum and Simon theory is capable of handling the effects of structure with its anchor-point postulate. The postulate is simple and powerful, capable of handling many types of stimulus-list structures. In the absence of identifiable structure, classical SP effects are predicted.

In conclusion, a general implication is that memory models that do not investigate and account for the effects of stimulus structure are limited in scope. If structured lists significantly alter the pattern of response by $S$, then it can only be further assumed that some current theories have to be modified to include memory mechanisms acting upon the stimulus structure.

\section{REI'ERENCES}

FEIGENBAUM, E. A., \& SIMON, H. A. A theory of the serial position effect. British Journal of Psychology, 1962, 53, 307-320.

LOESS, $H$. Short-term memory, word class, and sequence of items. Journal of Ixperimental Psychology, 1967, 74, 556-561.

NORMAN, D. A. Acquisition and retention in short-term memory. Journal of Experimental Psychology, 1966, 72, 369-381.

WAUGH, N. C., \& NORMAN, D. A. Primary memory. Psychological Review, 1965, 72, 89-104.

WICKENS, D. D., \& CLARK, S. Osgood dimensions as an encoding class in short-term memory. Journal of Experimental Psychology, $1968,78,580-584$.

WICKENS, D. D., CLARK, S. E., HILL, F. A., \& WITTLINGER, R. P. Investigation of grammatical class as an encoding category in short-term memory. Journal of Experimental Psychology, 1968, 78, 599-604.

$$
\text { NOTE }
$$

1. This research was supported, in part, by United States Public Health Service Research Grant MH 13192 to Wayne H. Bartz and conducted while the author was a graduatc rescarch assistant. 